\title{
Regional Overview on the Double Burden of Malnutrition and Examples of Program and Policy Responses: African Region
}

\author{
Adelheid W. Onyango $^{a}$ Juddy Jean-Baptiste ${ }^{b}$ Betty Samburu ${ }^{c}$ \\ Tshimi Lynn Moeng Mahlangu ${ }^{d}$ \\ ${ }^{a}$ Family and Reproductive Health Cluster, World Health Organization, Regional Office for Africa, Brazzaville, Republic

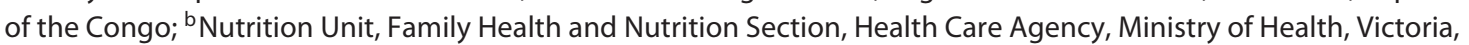 \\ Seychelles; ${ }^{\mathrm{C}}$ Nutrition and Dietetics Unit, Ministry of Health, Nairobi, Kenya; ${ }^{\mathrm{d}}$ Department of Health, North Western \\ University, Potchefstroom, South Africa
}

\section{Keywords}

Double burden of malnutrition - Sub-Saharan Africa .

Food environment . Unhealthy diet

\begin{abstract}
Sub-Saharan Africa is experiencing the double burden of malnutrition (DBM) with high levels of undernutrition and a growing burden of overweight/obesity and diet-related noncommunicable diseases (NCDs). Undernourishment in sub-Saharan Africa increased between 2010 and 2016. Although the prevalence of chronic undernutrition is decreasing, the number of stunted children under 5 years of age is increasing due to population growth. Meanwhile, overweight/obesity is increasing in all age groups, with girls and women being more affected than boys and men. It is increasingly recognized that the drivers of the DBM originate outside the health sector and operate across national and regional boundaries. Largely unregulated marketing of cheap processed foods and nonalcoholic beverages as well as lifestyle changes are driving consumption of unhealthy diets in the African region. Progress toward the goal of ending hunger and malnutrition by 2030 requires intensified efforts to
\end{abstract}

reduce undernutrition and focused action on the reduction of obesity and diet-related NCDs. The World Health Organization is developing a strategic plan to guide governments and development partners in tackling all forms of malnutrition through strengthened policies, improved service delivery, and better use of data. It is only through coordinated and complementary efforts that strides can be made to reduce the DBM.

(c) World Health Organization 2019 Published by S. Karger AG, Basel

\section{Introduction}

This paper presents a summary of discussions at the international symposium on the double burden of malnutrition (DBM) in December 2018 in a session that focused on the African region. Herein we review the epidemiology

The article is part of the Proceedings of the International Symposium on Understanding the Double Burden of Malnutrition for Effective Interventions organized by the International Atomic Energy Agency (IAEA) in cooperation with United Nations Children's Fund (UNICEF) and World Health Organization (WHO) (10-13 December 2018, Vienna, Austria).

\begin{tabular}{|c|c|}
\hline KARGER & $\begin{array}{l}\text { () World Health Organization } 2019 \\
\text { Published by S. Karger AG, Basel }\end{array}$ \\
\hline $\begin{array}{l}\text { E-Mail karger@karger.com } \\
\text { www.karger.com/anm }\end{array}$ & $\begin{array}{l}\text { All rights reserved. } \\
\text { This article is licensed under the Creative Commons Attribution- } \\
\text { NonCommercial-NoDerivatives } 4.0 \text { International License (CC BY- } \\
\text { NC-ND) (http://www.karger.com/Services/OpenAccessLicense). } \\
\text { Usage and distribution for commercial purposes as well as any dis- } \\
\text { tribution of modified material requires written permission. }\end{array}$ \\
\hline
\end{tabular}

Adelheid W. Onyango

Family and Reproductive Health Cluster

World Health Organization, Regional Office for Africa

Cité du Djoué, PO Box 06, Brazzaville (Republic of the Congo)

E-Mail onyangoa@who.int 
of the DBM with examples of program and policy responses to the challenge of the DBM. As well, we draw upon key examples where policies and DBM-control programs provide positive lessons that can be replicated throughout the region. We close with a discussion of the challenges and promise for future policies and programs in the region.

\section{Epidemiology and Landscape of the DBM in Africa}

The state of malnutrition in sub-Saharan Africa [1] is characteristic of the DBM with a high prevalence of undernutrition and increasing obesity along with diet-related noncommunicable diseases (NCDs) [2]. Considering that most countries will not meet the global nutrition targets by 2025 [3], it is unlikely that the region will achieve the Sustainable Development Goals of ending hunger and all forms of malnutrition by 2030 [4]. The prevalence of undernourishment in sub-Saharan Africa rose from 181 million in 2010 to 222 million in 2016 [5]. Although the prevalence of stunting among children under 5 years of age decreased between 2000 and 2017, the number of affected children increased from 50.6 to 58.7 million due to population growth. The prevalence of wasting in 2017 was 13.8 million children, of whom 4 million were severely wasted, showing that undernutrition remains a serious public health problem in this region of the world. At the same time, the number of overweight under-fives rose from 6.6 million in 2000 to 9.7 million in 2017 [6]. Among children and adolescents, the prevalence of obesity doubled between 2006 and 2016 to $2.1 \%$ in boys and $3.5 \%$ in girls as the prevalence of overweight/obesity for adults increased from $28 \%$ in 2000 to $42 \%$ in 2016 [2]. Thus, the number of countries in the African region with a high prevalence of the DBM continues to increase.

Among the drivers of the DBM, poverty-related factors, such as food insecurity and infectious diseases, persist as drought, floods, and protracted humanitarian crises continue to mark the face of Africa [7]. For overweight/obesity, cultural expectations and the early onset of puberty predispose girls to high adiposity. Cultural perceptions of female body size also drive the DBM as overweight is considered a sign of wealth, achievement, and marital harmony [8]. This cultural aspect, along with reduced physical activity, could explain why obesity is consistently higher in women compared to men.

Meanwhile, the consumption of processed foods is increasing at the expense of fresh and minimally processed foods. The commercialization of food production, processing, and distribution is correlated with decreasing smallholder farming, dietary diversity, and increasing household dependence on purchased foods, resulting in diets that are of low nutritional quality, energy-dense and high in sugars, salt, and fats [5]. The underlying causes of the DBM may vary by subregion, but the increasing consumption of cheap processed foods [9] and reduced physical activity are among the key drivers of the DBM.

\section{Program Experiences}

Current actions to address malnutrition in national multisectoral policies are inspired by the Lancet framework of nutrition-specific and nutrition-sensitive interventions with a predominant focus on reducing child undernutrition [10]. Attention to obesity and diet-related NCDs in Africa is growing, though there are still major challenges to defining and implementing the necessary measures to address their underlying causes.

According to the Second WHO Global Nutrition Policy Review [11], actions to prevent obesity and diet-related NCDs in Africa consist largely of diet/nutrition counseling, media campaigns, nutrient labeling, and issuing of dietary guidelines. However, to achieve higher public health impact, countries need regulatory measures to drive consumer choice toward healthful foods and/or decrease the desirability of unhealthful options [12], but such policies are not common in the African Region. For example, the WHO review found that no country banned industrial trans fats and only three (The Gambia, Liberia, and Mali) had regulations on the marketing of foods and nonalcoholic beverages to children [11]. Another report found that 17 African countries had no legal measures to control the marketing of breastmilk substitutes [13]. Therefore, the need to do more is great and is best achieved through regional and sectoral coordination and cooperation.

Lessons from South Africa's experience in developing policies provide a model for other countries in Africa. South Africa is implementing a tax on sugar-sweetened beverages as part of the national strategy to prevent and control obesity [14]. In developing this legislation, the government held consultations with various stakeholders, some of whom raised the concern that the tax would lead to job losses and interfere with citizens' freedom of choice [15]. Once adopted, the legislation was received reluctantly by the public, not having been part of the policymaking process, suggesting that consumers should be engaged in the development of regulations that affect their purchasing and consumption decisions. It was also suggested that greater public campaigns be made to promote the fact that the tax was being used to support the production of affordable, healthy foods to best encourage public buy-in of the legislation. 
A successful example from South Africa highlights the "Operation Sukuma Sakhe" (Let's Stand Together and Build!) in the Province of KwaZulu-Natal [16], a program coordinated by the KwaZulu-Natal's Premier's Office that has the authority to convene different sectors. Sukuma Sakhe rallies the people of KwaZulu-Natal to overcome issues affecting their communities, be it poverty, unemployment, crime, substance abuse, HIV/AIDS, or tuberculosis. Universities and research institutions are involved in building evidence for policy and providing technical expertise to the government. To ensure delivery of quality services, the role of the Provincial Nutrition Manager was raised to the rank of Director and mandated to make strategic decisions. Nutrition coordinators were appointed for each district, and community health workers were trained in nutrition. Monitoring and evaluation are core to the program's implementation and the intersectoral committee reports to the Premier quarterly. Among the positive achievements of the program are reductions in hospital admissions and fatality due to malnutrition, increased rates of exclusive breastfeeding, and a reduction in stunting.

Lessons are also available from Kenya where legislation was enacted to regulate the marketing of breast milk substitutes and create a supportive policy environment for its implementation. The Breastmilk Substitutes Act [17], enacted in 2012, was the result of concerted action by the government, in partnership with civil society and UN agencies, to create a conducive environment for breastfeeding. To support implementation of the Act, the government created a committee on infant and young child feeding (IYCF) and developed an implementation package that includes a monitoring and enforcement protocol. The Act has been an impetus for complementary initiatives to promote, protect, and support breastfeeding in the workplace [18]; the promotion of baby-friendly communities; and the adoption of updated WHO guidelines on IYCF where, with antiretroviral therapy, HIVpositive infants may be breastfed until the age of 2 years and beyond $[19,20]$. The implementation of the Act is moving forward, but it is challenged by slow progress in aligning the central and 47 county governments in its adoption and enforcement.

\section{Recommendations and Conclusions}

The downward trend in the prevalence of stunting belies the increasing number of chronically undernourished children in Sub-Saharan Africa [6]. Mean- while, overweight/obesity is increasing in all age groups, and diet-related NCDs are now among the main causes of premature death [2]. The observation that obesity could negate benefits that have contributed to increased life expectancy [21] holds true for the African region.

The sessions during the symposium highlighted several elements that are important for the success of policies and programs. Since the food environment is a strong driver of the DBM, policies and interventions, supported by strong leadership, funding, monitoring systems, standards and guidelines are needed to control the consumption of unhealthy foods. The policies should restrict the marketing of unhealthy foods to children (e.g., as part of school meals in canteens and at sales points within defined limits of schools), while encouraging students to be positive change agents. In addition to promoting healthful diets, the African region needs to enforce food labeling, restrictions on health claims of products, and reformulation of products so that consumers can make informed choices. Regulation of the nutritional and health quality of foods and beverages that are promoted for consumption by commercial entities is important to protect consumers in Africa.

To address the DBM, programs targeting socioeconomically disadvantaged groups are needed to prevent undernutrition. Policies should be developed to increase the availability and affordability of diverse, healthy foods and to disincentivize the consumption of unhealthy foods and beverages. Interventions targeting undernutrition can serve a double duty by preventing or reducing obesity, for example, universal access to clean drinking water would reduce diarrhea-driven undernutrition and the consumption of sugar-sweetened beverages, while appropriate IYCF prevents undernutrition as well as obesity.

Government leadership is necessary to create policies and enabling environments needed for their implementation. Civic participation in policy dialogue is an important part of stakeholder engagement to ensure that policies gain acceptance. Successful implementation of programs requires that they are evidence based with the capacity to deliver appropriate services at the grassroots level. For Sub-Saharan Africa, evidence is urgently needed on the economic costs of the DBM and on the inequities accompanying economic growth to make the case for targeted action. To this end, the WHO Regional Office for Africa will facilitate the creation of a network of researchers as an institutional resource to support sound nutrition policies in Africa. 


\section{Acknowledgments}

Acknowledgment of the International Atomic Energy Agency for organizing the symposium and sponsoring the participation of session speakers from Kenya, Seychelles, and South Africa. Shane Norris contributed to the content of this paper in a session presentation on the epidemiology of the DBM in Africa. Martha Mwangome, Augustin Nawidimbasba Zeba, and Merlyn Chapfunga were rapporteurs for the session and provided notes that informed the preparation of this paper.

\section{Statement of Ethics}

The authors have no ethical conflicts to disclose for this review because there were no humans or animals involved directly.

\section{Disclosure Statement}

The authors have no conflicts of interest to declare.

\section{Funding Sources}

No funding was provided for the preparation of the manuscript. Open access provided with a grant from the International Atomic Energy Agency.

\section{Author Contributions}

A.W.O. conceptualized the symposium session and led the drafting and revision of the manuscript with inputs from J.J.-B., B.S., and T.L.M.M. All authors have read and approved the final version of the manuscript.

\section{Disclaimer}

The statements, opinions and data contained in this publication are solely those of the individual authors and contributors, not of the publishers and the editor(s), and do not necessarily reflect the views of the cooperating organizations, IAEA, UNICEF and WHO. The use of particular designations of countries or territories does not imply any judgement by the cooperating organizations, as to the legal status of such countries or territories, of their authorities and institutions or of the delimitation of their boundaries. The mention of names of specific companies or products (whether or not indicated as registered) does not imply any intention to infringe proprietary rights, nor should it be construed as an endorsement or recommendation on the part of the cooperating organizations.

\section{References}

1 World Health Organization. Nutrition in the WHO African Region. Brazzaville: World Health Organization; 2017.

2 World Health Organization. Atlas of African Health Statistics 2018: universal health coverage and the Sustainable Development Goals in the WHO African Region. Brazzaville: WHO Regional Office for Africa; 2018.

3 Development Initiatives. 2018 Global Nutrition Report: Shining a light to spur action on nutrition. Bristol: Development Initiatives; 2018.

4 United Nations Economic and Social Council. Report of the Inter-Agency and Expert Group on Sustainable Development Goal Indicators (E/CN.3/2016/2/Rev.1), Annex IV. New York: United Nations; 2015.

5 Food and Agriculture Organization, International Fund for Agricultural Development, UNICEF, World Food Programmes and World Health Organization. The State of Food Security and Nutrition in the World 2018. Building climate resilience for food security and nutrition. Rome, Food and Agriculture Organization; 2018.

6 UNICEF/ World Health Organization/World Bank. Joint child malnutrition estimates, 2018 edition. http://www.who.int/nutgrowthdb/ estimates2017/en/.

7 Carroll GJ, Lama SD, Martinez-Brockman JL, Pérez-Escamilla R. Evaluation of Nutrition Interventions in Children in Conflict Zones:
A Narrative Review. Adv Nutr. 2017 Sep;8(5): $770-9$.

8 Okop KJ, Mukumbang FC, Mathole T, Levitt N, Puoane T. Perceptions of body size, obesity threat and the willingness to lose weight among black South African adults: a qualitative study. BMC Public Health. 2016 Apr; 16(1):365.

9 Holmes MD, Dalal S, Sewram V, Diamond MB, Adebamowo SN, Ajayi IO, et al. Consumption of processed food dietary patterns in four African populations. Public Health Nutr. 2018 Jun;21(8):1529-37.

10 Black RE, Victora CG, Walker SP, Bhutta ZA, Christian P, de Onis M, et al.; Maternal and Child Nutrition Study Group. Maternal and child undernutrition and overweight in lowincome and middle-income countries. Lancet. 2013 Aug;382(9890):427-51.

11 World Health Organization. Global nutrition policy review 2016-2017: country progress in creating enabling policy environments for promoting healthy diets and nutrition. Geneva: World Health Organization; 2018

12 Frieden TR. A framework for public health action: the health impact pyramid. Am J Public Health. 2010 Apr;100(4):590-5.

13 World Health Organization, UNICEF and International Baby Food Action Network. Marketing of breast-milk substitutes: National implementation of the International Code status report 2018. Geneva: World Health Organization; 2018.

14 Department of Health. Strategy for the prevention and control of obesity in South Africa 2015-2020. Pretoria: Republic of South Africa; 2016.

15 South African Revenue Services. Final Response Document on the 2017 Rates and Monetary Amounts and Amendment of Revenue Laws Bill - Health Promotion Levy, 2017. Pretoria: Republic of South Africa; 2017.

16 Office of the Premier. Operation Sukuma Sakhe. Operations Handbook. Pietermaritzburg: Province of KwaZulu Natal; 2015.

17 Government of Kenya. Breast Milk Substitutes (Regulation and Control) Act, 2012.

18 Government of Kenya. The Health Act, 2017.

19 Ministry of Health. Guidelines on use of Antiretroviral Drugs for Treating and Preventing HIV in Kenya. Nairobi: Government of Kenya; 2018.

20 World Health Organization /UNICEF. Guideline: Updates on HIV and infant feeding: the duration of breastfeeding, and support from health services to improve feeding practices among mothers living with HIV. Geneva: World Health Organization; 2016.

21 World Health Organization. Report of the Commission on Ending Childhood Obesity. Geneva: World Health Organization; 2016. 